Boise State University

ScholarWorks

Anthropology Faculty Publications and

Presentations

Department of Anthropology

2004

Nonmarket Cooperation in the Indigenous Food Economy of Taimyr, Arctic Russia: Evidence for Control and Benefit

John Ziker

Boise State University

This document was originally published by Cambridge University Press in Behavioral and Brain Sciences. Copyright restrictions may apply. DOI: 10.1017/S0140525X04340124 
ACKNOWLEDGMENTS

Avishag Zahavi has been a partner to the development of the text and Naama Zahavi-Ely improved its presentation.

\section{Nonmarket cooperation in the indigenous food economy of Taimyr, Arctic Russia: Evidence for control and benefit}

\section{John Ziker \\ Department of Anthropology, Boise State University, Boise, ID 83702-1950. jziker@boisestate.edu}

\begin{abstract}
Empirical data on food sharing in native Dolgan, Nganasan, and Nenets communities in Siberia provide evidence for hunter control over big game and fish, as well as likely benefits of inter-household sharing. Most food sharing occurs with kin and, thus, kin-selection-based nepotism cannot be ruled out. Reciprocal interhousehold sharing at meals occurs less often. Social context is discussed.
\end{abstract}

After describing four evolutionary hypotheses on hunter-gatherer food sharing, Gurven presents four key latent variables useful as indicators for evaluating nonmarket food transfer documented in ethnographic settings: depth, breadth, equality, and balance. Specific combinations of values for these variables as predictions for the explanatory models make the article a valuable contribution for those collecting field data on food sharing in the human-behavioral-ecology framework. Potential complications include: the specific combination of strategies characterizing food transfer based on given relationships in an ego's social network, the stage of food distribution, the type of resource being procured, the position in the life cycle, and local definitions of success.

Empirical research on food sharing among Dolgan and Nganasan in the Taimyr Autonomous Region in the Siberian Arctic shows the influence of a number of variables and models depending on the social context. For example, in the 1995-to-1996 period, 814 food-consumption events were observed in three types of locations in everyday settings. Of these meals, 546 cases included two or more native participants. In the regional capital, Dudinka, the majority of dyadic relationships at shared meals comprised mostly cognatic relatives, along with some friends. The majority of participants were female. In remote communities, including Ust'-Avam, Tukhard, and Kresty-Taimyrskii, cognatic dyads were less common but spouse and affine dyads had higher frequencies at shared meals. In most cases, affines represented a visiting household. During hunting trips, at reindeer herding camps, and at remote houses in the tundra, males who are close cognatic relatives and friends were the predominant participants at meals. The village and bush were the contexts under which more interhousehold food sharing occurred.

A thorough analysis of food sharing for five households in the Ust'-Avam area resulted in an interconnected network of 50 households. Seventeen households were considered to constitute the core because the elimination of one dyadic household link within this group would not isolate any of the other households. The remaining 33 households were peripheral actors, often connected through one link only. Focusing on household dyads, just over half were households related by kinship (44 of 84). Households related by cognatic kinship were associated with the majority (331) of interhousehold-meal observations (total 439) in Ust'-Avam and nearby bush. Following predictions from inclusive-fitness theory (Hamilton 1964) and generalized-reciprocity theory (Sahlins 1972), resource flow in this sample was most asymmetrical among pairs of households related by close kinship. This asymmetry includes household relationships exhibiting one-way flows of resources, especially from households with high producer-to-consumer ratios to households exhibiting lower consumer-to-producer ratios (i.e., young families). The context of much of this interhousehold sharing is one of children visiting and eating at their grandparents' or aunt's and uncle's house, providing further support for inclusive-fitness benefit.

Although non-kin also received meals in a one-way flow, such sharing relationships were less common - one household, consisting of an unrelated friend from outside the village, was hosted throughout her one-week visit; in another case, a young apprentice was hosted throughout a hunting expedition. Resource flow was more symmetrical, on average, between unrelated households, following expectations for reciprocal altruism and balanced reciprocity. Meals hosted between non-relatives show more balance. Meals hosted with kin show depth and bias towards relatives with children.

In a recent study, a number of independent variables were regressed on the interhousehold food-sharing network (Ziker, n.d.). The presence or absence of a kinship link between households was the most consistent predictor of interhousehold food sharing at meals. The physical proximity of households to one another is a marginal and weak explanatory variable, which drops out of significance when other variables are added. Because housing was assigned to families as it was built and became available in the 1970s through early 1990s in Taimyr villages, relatives were rarely assigned living quarters in close proximity. Kinship strongly influences food-sharing patterns independent of household location.

Reciprocal food-sharing relationships comprised 26 of the 84 household dyads (11 pairs of households in the core and 2 pairs of core-periphery households). When rank-order average household relatedness was compared to the rank of meals exchanged, the Pearson correlation $(0.663)$ was significant $(p=0.014$; two-tailed). Genealogical relatedness structures reciprocity, and the unrelated household dyads ( 3 of 13 pairs) received small total percentages of food shared at meals. The depth of sharing with relatives (and the asymmetry in the direction of young households) is highly evocative of kin selection-based nepotism.

Local social definitions of cultural success and proper behavior are also important for understanding food-sharing patterns among Dolgan and Nganasan. Hunters generally transfer the majority of procured meat and fish to their elders or spouses upon returning to the village, which implies a high degree of control over resources but a conversion to family property (Ziker 2002a). The elders or spouses (many of whom are the keepers of keys to storage areas) redistribute the raw food to their close relatives, especially those with children, as well as to friends and acquaintances in the form of either raw food or meals. Hunters and their families give to those people who ask for food (especially single mothers and pensioners), but they usually give relatively small portions of raw food and host such people at meals more rarely than relatives.

Although control is exerted at the kill and upon returning to the village, local understandings of property require hunters or their relative to share some portions of the catch with other people (otherwise "the hunt simply would not happen"). In cooperative hunts or fishing, the catch is usually divided equally among the participants. Signalling through food sharing likely factors into establishing long-term cooperative relationships with non-kin. Food sharing with kin may also carry a signalling function in terms of respect for elders and caring for relatives, who are supplied with food without asking. This is not to say that food sharing creates kin per se but that hypothetical signalling effects should not be limited to mating effort and long-term social-relationship building outside of kin. It is not clear that consistently generous individuals receive prestige, support, or social insurance beyond kin and close friends. Although claims of stinginess could carry a social cost reducing the benefit of hunter control, such communication is reserved for cases where the social relationship has already soured. 